\title{
An Investigation of Steel Fiber Reinforced Concrete with Fly Ash
}

\author{
Khadake S.N. ${ }^{1}$, Konapure C.G. ${ }^{2}$ \\ ${ }^{I}$ (P. G. Student, Department of Civil-Structures, W. I. T. Solapur, Solapur University, India) \\ ${ }_{2}^{2}$ (Assistant Professor, Department of Civil-Structures, W. I. T. Solapur, Solapur University, India)
}

\begin{abstract}
This paper deals with Investigation for M-25 grade of concrete having mix proportion 1:1.50:3.17 with water cement ratio 0.465 to study the compressive strength, and Flexural strength of steel fiber reinforced concrete (SFRC) containing fibers of an interval of $0.5 \%$ from $0.0 \%$ to $1.5 \%$ volume fraction of hook end Steel fibers of 71 aspect ratio were used. The percentage of Fly Ash by weight is to be increased by $10 \%$ from $00 \%$ to $30 \%$. After curing these specimen were tested as per relevant codes of practice Bureau of Indian Standard. A result data obtained has been analyzed and compared with a control specimen. A relationship between Compressive strength vs. days, and flexural strength vs. days represented graphically. Result data clearly shows percentage increase in 7, 28 \& 45 days Compressive strength for M-25 Grade of Concrete.
\end{abstract}

Keywords - Fiber Reinforced concrete, Fly Ash, Mix Design, steel fiber, Strength.

\section{Introduction}

Concrete is very strong in compression but weak in tension. As a Concrete is a relatively brittle material, when subjected to normal stresses and impact loads. The tensile strength of concrete is less due to widening of micro-cracks existing in concrete subjected to tensile stress. Due to presence of fiber, the micro-cracks are arrested. The introduction of fibers is generally taken as a solution to develop concrete in view of enhancing its flexural and tensile strength.

Fly ash is the fine powder major waste material produced from many thermal power plants. The disposal of fly ash is the one of the major issue for environmentalists as dumping of fly ash as a waste material may cause severe environmental problem. Therefore, the utilization of fly ash as an low cost mineral admixture in concrete instead of dumping it as a waste material can have great beneficial effects. It can be used particularly in mass concrete applications where main emphasis is to control the thermal expansion due to heat of hydration of cement paste and it also helps in reducing thermal and shrinkage cracking of concrete at early ages. The replacement of cement with fly ash in concrete also helps to conserve energy. The introduction of the paper should explain the nature of the problem, previous work, purpose, and the contribution of the paper. The contents of each section may be provided to understand easily about the paper.

\section{Role of Fiber Reinforced Fly Ash Concrete}

Fiber reinforced concrete (FRC) is mixtures of cement concrete containing short discrete, uniformly dispersed and randomly oriented suitable fibrous material which increases its structural integrity. The amount of fibers added to concrete mix is measured as percentage of the total volume of composites. Aspect ratio ( $1 / \mathrm{d})$ is calculated by dividing fiber length (1) by its diameter (d).

The composite matrix that is obtained by combining cement, Fly ash, aggregates and fibers is known as "Fly ash Fiber reinforced concrete". The fiber in the cement fly ash based matrix act s as crack - arresters, which restrict the growth of micro cracks and prevent these from enlarging under load.

\section{Material Specifications}

\section{Cement}

The cement used in this experimental work is 43 grades Ordinary Portland Cement. All properties of cement are tested by referring IS 12269 - 1987 Specification for 43 Grade Ordinary Portland cement. The specific gravity of the cement is 3.15 . The initial and final setting times were found as 90minutes and 180 minutes respectively. Standard consistency of cement was $31.25 \%$.

\section{Fine aggregate}

Locally available sand passed through $4.75 \mathrm{~mm}$ IS sieve is used. The specific gravity of 2.84 and fineness modulus of 3.895 are used as fine aggregate. The loose and compacted bulk density values of sand are $1094 \mathrm{and} 1162 \mathrm{~kg} / \mathrm{m} 3$ respectively, the water absorption of $1.491 \%$. 


\section{Coarse Aggregate}

20MSA:-Crushed aggregate available from local sources has been used. The coarse aggregates with a maximum size of $20 \mathrm{~mm}$ having the specific gravity value of 2.958 and fineness modulus of 7.136 are used as coarse aggregate. The loose and compacted bulk density values of coarse aggregates are 1467 and $1629 \mathrm{~kg} / \mathrm{m} 3$ respectively, the water absorption of $1.30 \%$.

10MSA:-Crushed aggregate available from local sources has been used. The coarse aggregates with a maximum size of $10 \mathrm{~mm}$ having the specific gravity value of 3.016and fineness modulus of 5.829 are used as coarse aggregate. The loose and compacted bulk density values of coarse aggregates are 1531 and $1726 \mathrm{~kg} / \mathrm{m} 3$ respectively, the water absorption of $1.835 \%$.

\section{Water}

Potable water used for the experimentation.

\section{Fibers}

The steel fiber is procured from precision Drawell Pvt. Ltd., Nagpur. The steel fiber used in the study is the hook ended type HK0750 having aspect ratios 71 . The constant dosages of $0.5 \%$ fibers up to $1.5 \%$ are used by total volume of concrete. The length of dividing fiber is $50 \mathrm{~mm}$ and the diameter of fiber is 0.7 .

\section{Fly Ash}

Fly Ash is available in dry powder form and is procured from Dirk India Pvt. Ltd., Nasik. The light gray, fly ash under the product name "Pozzocrete 60 " is available in $30 \mathrm{~kg}$ bags. The Fly ash produced by the company satisfies all the requirements of the IS 3812: 1981, BS 3892: Part I: 1997.

\section{Mix Design}

Mix design is known as the selection of mix ingredients and their proportions required in a concrete mix. In the present study method for mix design is the Indian Standard Method. The mix design involves the calculation of the amount of cement, fine aggregate and coarse aggregate in addition to other related parameters dependent on the properties of constituent material. The modifications are made and quantities of constituent materials used to cast Fly Ash Fiber Reinforced concrete. The proportions for normal mix of M25 Normal Mix are as follows: - Cement: Sand: Coarse Aggregate: Water

$$
1 \quad: 1.50: \quad 3.17 \quad: 0.465
$$

\section{Batching, Mixing and casting}

Careful procedure was adopted in the batching, mixing and casting operations. The coarse Aggregates and fine aggregates were weighed first with an accuracy of 0.5 grams. The Concrete mixture was prepared by hand mixing on a watertight platform. The fly ash and Cement was mixed dry to uniform colour separately. On the watertight platform, the coarse and fine aggregates were mixed thoroughly. To this mixture, the required quantity of cement, fly ash and fibers (Fly ash $10 \%$ by weight of cement and fibers $0.5 \%$ ) were added. These were mixed to uniform colour. Then water was added carefully so that no water was lost during mixing. The moulds were filled with $0.0 \%, 0.5 \%, 1.0 \%$ and $1.5 \%$ fibers. Fly Ash (00\% to $30 \%$ by weight of cement) was added to this. Vibration was given to the cube moulds using table vibrator. The top surface of the specimen was leveled and finished. After 24 hours the specimens were demoulded and were transferred to curing tank where in they were allowed to cure for $7,28 \& 45$ days.

\section{Workability Test}

\section{Experimental Methodology}

Workability is carried out by conducting the slump test and compaction factor test as shown in Fig. 1 \& Fig. 2 As per I.S. 1199-1959 on ordinary concrete and fiber reinforced concrete.

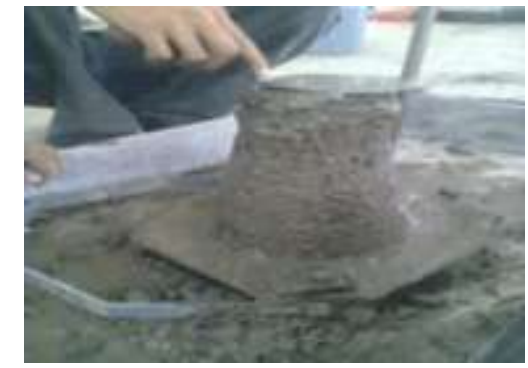

Fig. 1.Slump Test

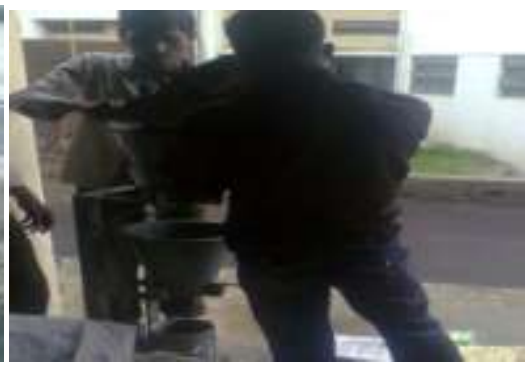

Fig. 2. Compaction Factor Test 


\section{Compressive strength test}

The compressive strength of concrete is one of most important properties of concrete in most structural applications. For compressive strength test, cube specimens of dimensions 150 x 150 x $150 \mathrm{~mm}$ were cast for M25 grade of concrete. After curing, these cubes were tested on Compression Testing machine as shown in Fig. 3 As per I.S. 516-1959. The failure load was noted. In each category two cubes were tested and their average value is reported. The compressive strength was calculated as follows, Compressive strength $(\mathrm{MPa})=$ Failure load / cross sectional area.

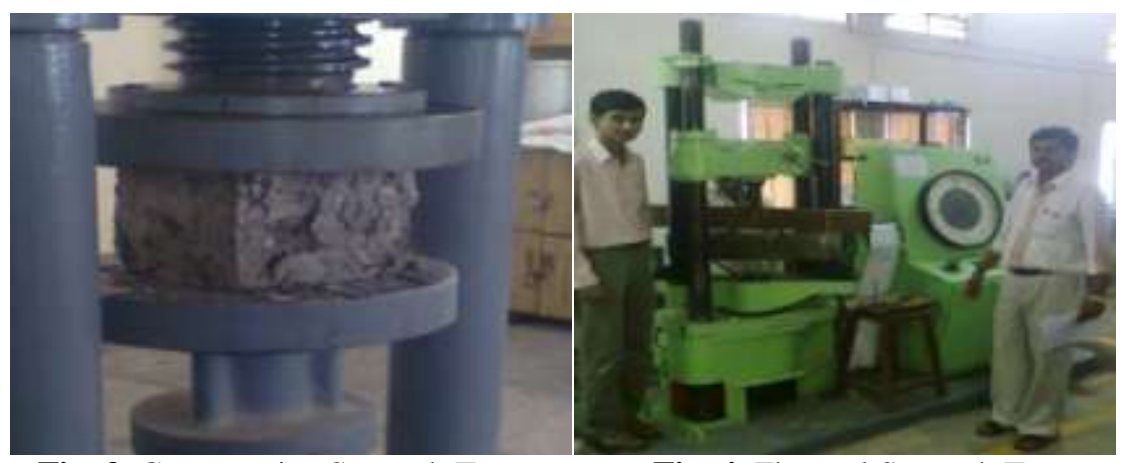

Fig. 3. Compressive Strength Test

Fig. 4. Flexural Strength Test

\section{Flexural strength test}

For flexural strength test beam specimens of dimension 150x150x700 mm were cast. The specimens were demoulded after 24 hours of casting and were transferred to curing tank where in they were allowed to cure for 7 days. These flexural strength specimens were tested under two point loading as per I.S. 516-1959, over an effective span of $600 \mathrm{~mm}$ divide into three equal parts and rest on Flexural testing machine as shown in Fig. 4. The load is normally increased \& failure load is noted at cracking of beam specimen. In each category two beams was tested and their average value is reported. The flexural strength was calculated as follows.

Flexural strength $(\mathrm{MPa})=(\mathrm{P} \times \mathrm{L}) /\left(\mathrm{b} \times \mathrm{d}^{2}\right)$,

Where, $\mathrm{P}=$ Failure load, $\mathrm{L}=$ Centre to centre distance between the support $=600 \mathrm{~mm}, \mathrm{~b}=$ width of specimen $=150 \mathrm{~mm}, \mathrm{~d}=$ depth of specimen $=150 \mathrm{~mm}$.

The entire specimen was tested in the Structural Engineering laboratory of Walchand Institute of Technology, Solapur.

\section{Fresh Concrete Test Results}

\section{Experimental Result}

The properties of fresh concrete can be evaluated by slump cone test \& compaction factor test with $\mathrm{W} / \mathrm{C}$ ratio 0.465 .The result of properties are given in Table No.1.

Table No.1:-Result of Slump, Compaction Factor and Density of Fresh Concrete

\begin{tabular}{|c|c|c|c|c|}
\hline $\begin{array}{c}\text { Sr. } \\
\text { No. }\end{array}$ & Mix Type (SF\%\&FA \%) & $\begin{array}{c}\text { Slump } \\
\text { Value }(\mathrm{mm})\end{array}$ & $\begin{array}{c}\text { Compaction } \\
\text { Factor }\end{array}$ & Density $\left(\mathrm{kg} / \mathrm{m}^{3}\right)$ \\
\hline 01 & MS0 (0.0\%\&00\%) & 65 & 0.964 & 2574.81 \\
\hline 02 & MS1 $(0.5 \% \& 10 \%)$ & 15 & 0.797 & 2586.67 \\
\hline 03 & MS2 (0.5\%\&20\%) & 29 & 0.809 & 2560.00 \\
\hline 04 & MS3 (0.5\%\&30\%) & 40 & 0.890 & 2554.07 \\
\hline 05 & MS4 (1.0\%\&10\%) & 09 & 0.793 & 2613.33 \\
\hline 06 & MS5 (1.0\%\&20\%) & 11 & 0.796 & 2577.78 \\
\hline 07 & MS6 (1.0\%\&30\%) & 26 & 0.802 & 2560.00 \\
\hline 08 & MS7 (1.5\%\&10\%) & 07 & 0.730 & 2640.00 \\
\hline 09 & MS8 (1.5\%\&20\%) & 09 & 0.780 & 2610.37 \\
\hline 10 & MS9 (1.5\%\&30\%) & 10 & 0.794 & 2588.00 \\
\hline
\end{tabular}

\section{Hardened Concrete Strength Results}

2.1. Compressive Strength - Result of compressive strength for M25 grade of concrete on cube. The specimens are separated by steel fiber \& Fly ash with varying percentage. The Table No. 2 \& Fig No.5 Shows result of compressive strength at $7,28 \& 45$ days. 
Table No.2:- Compressive strength $\left(\mathrm{N} / \mathrm{mm}^{2}\right)$ at 7, 28 and 45 Days

\begin{tabular}{|c|c|c|c|c|c|}
\hline Mix. No. & Steel Fiber\% & Fly Ash\% & \multicolumn{3}{|c|}{ Compressive Strength(N/mm $\left.{ }^{2}\right)$} \\
\hline & & & 7 Days & 28 Days & 45 Days \\
\hline MS0 & $0.0 \%$ & $00 \%$ & 19.517 & 33.350 & 33.35 \\
\hline MS1 & $0.5 \%$ & $10 \%$ & 23.155 & 27.603 & 35.17 \\
\hline MS2 & $0.5 \%$ & $20 \%$ & 17.315 & 24.280 & 27.35 \\
\hline MS3 & $0.5 \%$ & $30 \%$ & 15.360 & 19.895 & 21.92 \\
\hline MS4 & $1.0 \%$ & $10 \%$ & 23.905 & 29.290 & 44.51 \\
\hline MS5 & $1.0 \%$ & $20 \%$ & 21.470 & 30.635 & 34.78 \\
\hline MS6 & $1.0 \%$ & $30 \%$ & 22.190 & 25.460 & 33.46 \\
\hline MS7 & $1.5 \%$ & $10 \%$ & 26.695 & 31.545 & 45.88 \\
\hline MS8 & $1.5 \%$ & $20 \%$ & 16.575 & 27.455 & 37.51 \\
\hline MS9 & $1.5 \%$ & $30 \%$ & 16.920 & 26.665 & 27.23 \\
\hline
\end{tabular}

Fig.No.5:- Type of Mix vs. Compressive Strength $\left(\mathrm{N} / \mathrm{mm}^{2}\right)$ at 7, 28 \& 45 Days

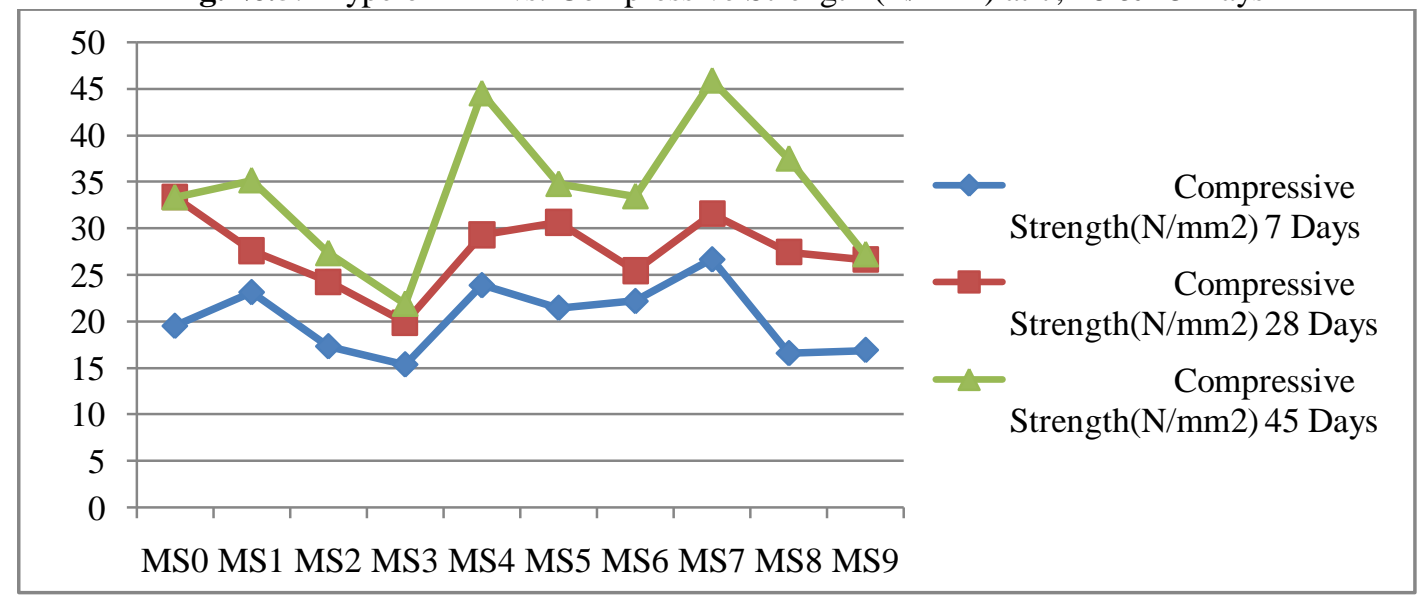

2.2. Flexural Strength

The Table No.3 \& Fig.No.6 shows Flexural Strength of beam specimen at 7 days.

Table No.3:- Flexural Strength $\left(\mathrm{N} / \mathrm{mm}^{2}\right)$ at 7 Days

\begin{tabular}{|c|c|c|c|}
\hline Mix. No. & Steel Fiber\% & Fly Ash\% & $\begin{array}{c}\text { Flexural } \\
\text { Strength(N/mm }{ }^{2}\end{array}$ \\
\hline & & & 7 Days \\
\hline MS1 & $0.5 \%$ & $10 \%$ & 3.213 \\
\hline MS2 & $0.5 \%$ & $20 \%$ & 2.332 \\
\hline MS3 & $0.5 \%$ & $30 \%$ & 2.344 \\
\hline MS4 & $1.0 \%$ & $10 \%$ & 3.936 \\
\hline MS5 & $1.0 \%$ & $20 \%$ & 3.058 \\
\hline MS6 & $1.0 \%$ & $30 \%$ & 3.697 \\
\hline MS7 & $1.5 \%$ & $10 \%$ & 5.308 \\
\hline MS8 & $1.5 \%$ & $20 \%$ & 4.198 \\
\hline MS9 & $1.5 \%$ & $30 \%$ & 2.979 \\
\hline
\end{tabular}




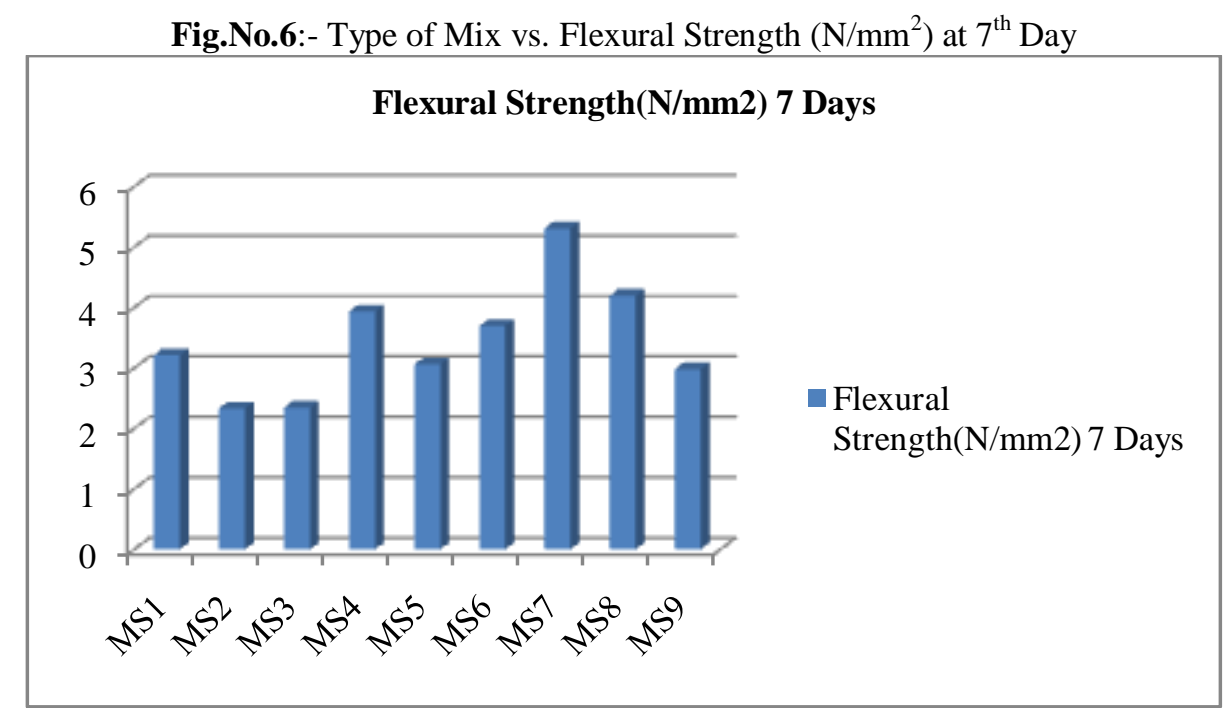

\section{Conclusions}

The study on the effect of steel fibers with Fly Ash can still be a promising work as there is always a need to overcome the problem of brittleness of concrete. The following conclusions could be drawn from the present investigation.

1. Marginal increase is observed in the workability as percentage of Fly Ash increases.

2. Density of concrete is more as the percentage of steel Fiber increases with Fly Ash content $10 \%$.

3. Compaction factor is increases as the Steel Fiber percentage decreases.

4. Higher percentage of Steel Fibers slump was losing.

5. Water reducing agent is required for workable mix as percentage of Steel Fiber increases.

6. Stiffness of specimens is increased because of Steel Fibers \& Fly Ash.

7. The strength of specimen is about $80 \%$ at $28^{\text {th }}$ day and 95 to $100 \%$ at 45 days, because of steel fiber \& Fly Ash.

8. Specimen of MS4, MS7\&MS8 having high Flexural strength as well as Compressive strength.

9. For small quantity of Fly Ash $(10 \% \& 20 \%)$ Compressive Strength is more for $1.0 \%$ \& $1.5 \%$ Steel Fibers.

\section{References}

[1] B. Krishna Rao, V. Ravindra(2010), "Steel Fiber Reinforced Self compacting Concrete Incorporating Class F Fly Ash", International Journal of Engineering Science and Technology Vol. 2(9),4936-4943.

[2] Falah A. Almottiri (2011), "Physical Properties of Steel Fiber Reinforced Cement Composites Made with Fly Ash", Jordan Journal of Civil Engineering, Volume 5, No. 2.

[3] Chih-Ta Tsai, Lung-Sheng Li, Chien-Chih Chang, Chao-Lung Hwang (2009), "Durability Design and Application of Steel Fiber Reinforced Concrete in Taiwan", the Arabian Journal for Science and Engineering, Volume 34, Number 1B.

[4] Osman Gencel, Witold Brostow, Tea Datashvili and Michael Thedford (2011), "Workability and Mechanical Performance of Steel Fiber-Reinforced Self-Compacting Concrete with Fly Ash, Composite Interfaces 18,169-184.

[5] IS: 10262-2009, Recommended guidelines for concrete mix design, Bureau of Indian standards, New Delhi, India

[6] IS 383:1970, Specification for coarse and fine aggregates from natural sources for concrete (second revision), Bureau of Indian standards, New Delhi, India.

[7] IS: 516-1959, Indian standard methods of tests for strength of concrete, Bureau of Indian Standards, New Delhi, India.

[8] Falah M.Wegian,Anwar A.Alanki,Hana M.Alsaeid,Fahad A.Alotaibi(2011), "Influence of Fly Ash on Behavior of Fiber Reinforced Concrete Structures", Journal of Applied Sciences,11(17):3185-3191.

[9] Ilker Bekir Topcu, M. Canbaz (2007), "Effect of different fibers on the mechanical properties of concrete containing fly ash Construction" and Building Materials 21,1486-1491. 